\title{
A escrita científica da ciência portuguesa: Algumas métricas das ciências sociais e psicológicas
}

\author{
Rui Pedro Tinoco ${ }^{1} \&$ José Luís Fernandes ${ }^{2}$ \\ ${ }^{1}$ DICAD - ARS Norte, IP \\ ${ }^{2}$ Faculdade de Psicologia e Ciências de Educação da Universidade do Porto
}

\begin{abstract}
Resumo: Neste trabalho, procuramos conhecer as formas que a escrita científica da ciência portuguesa, nomeadamente das ciências sociais e psicológicas, assumem em termos de grandes bases de dados internacionais. Para isso, pesquisámos a produção científica tendo como principais instrumentos a PorData; a Scimago; a Scopus; Web of Science e a Journal of Citation Report. Interessou-nos saber quais as unidades de contagem do impacto; de que forma se organizam as autorias; os temas de escrita; a presença das revistas científicas portuguesas nessas bases de dados; as valorizações e rankings em que surge a produção nacional e, finalmente, quisemos identificar outras métricas, para além das nomeadas inicialmente, que começam agora surgir.
\end{abstract}

Palavras-chave: Publicação Científica; Epistemologia; Escrita Científica; Psicologia.

The scientific writing of the Portuguese Science: Some metrics from the social sciences and psychology: In this work we try to know the ways in which the portuguese science writing, mainly the national social science and psychological writing, appears in the biggest scientific databases of the world. To reach that aim we research the national scientific production using PorData; Scimago; Scopus; Web of Science and the Journal of Citation Report. We wanted to know the kind of scores use to evaluate the scientific impact; the authorships patterns; the paper's main themes; the presence of national scientific journal in the international arena. Finally, we wanted to identify other metrics that started to show up.

Keywords: Scientific Publication; Epistemology; Scientific Writing; Psychology.

"This paper suggests that it is the best and worst of times for academic work. It is the best of times because there are more academics publishing than ever before. It is the worst of times because there is much unnecessary publication" Michael Billig (2013)

\section{Sociedade do conhecimento, publicação científica e capitalismo cognitivo}

As rápidas e profundas mudanças que as últimas décadas testemunham têm vindo a ser mapeadas e caracterizadas por uma série de analistas da contemporaneidade, propondo-se designações cujos nomes encerrariam alguns dos traços centrais destas mudanças: reconfiguração do capitalismo em direção a uma financeirização da economia global, modernidade tardia, desmodernização, sociedades pós-industriais, sociedade líquida, sociedade de risco, sociedade dos indivíduos. Aparecem ainda expressões como "dealbar duma nova era" e "quarta revolução industrial2.

Mas interessa-nos sobretudo a expressão "sociedade do conhecimento", pois coloca a tónica na produção de saber e nos seus modos de circulação e apropriação, marcados pelas novas tecnologias de informação. A expressão assinala o caráter estratégico que tem hoje a posse do conhecimento. Se nas fases anteriores do capitalismo, a mercadoria ocupava o centro do espaço de mercado, o conhecimento ocupa também hoje este lugar. E, porque tem um custo, um valor de troca e uma importância estratégica nas relações de produção, podemos assimilá-lo simbolicamente a uma mercadoria. A mercadoria é objeto de desejo e incita à posse porque gera lucro. Assim é também com o conhecimento situado agora no espaço de mercado: objeto de desejo e incitando à posse, está no centro do capitalismo cognitivo. Martinez e Tarrès (2013, p. 142) definem-no assim:

${ }^{1}$ Morada para correspondência: Rui Pedro Tinoco, DICAD - ARS Norte, IP. Rua da Constituição, no 195 - 4o - 4200-198 Porto, Portugal. E-mail: ruitinoco28@gmail.com

2 Os autores que associamos a estas expressões vêm dos campos da economia, da história, da sociologia e da filosofia: Anthony Giddens, Alain Touraine, Zigmunt Bauman, Ulrich Beck, Gilles Lipovetsky, Norbert Elias, só para citar alguns. 
“(...) el concepto de capitalismo cognitivo (Blondeau et al. 2004) resulta un elemento heurístico que ayuda a reflexionar sobre las nuevas tendencias de producción en las que se pone la "vida a trabajar" a través de la explotación de las capacidades creativas, afectivas y relacionales de las personas que son cooptadas por la producción capitalista en las actuales dinámicas de reproducción y mercantilización del conocimiento (Virno, 2003). En esta configuración, producto de los diferentes procesos de expansión e intensificación de las lógicas del mercado, el conocimiento, la información y las relaciones son medios de producción y mercancías susceptibles de objetivación (Expósito, 2007)”.

Nas condições que acabamos muito sumariamente de descrever, a publicação tem vindo a tornar-se central. As revistas científicas são desde há muito importantes veículos no funcionamento das comunidades científicas. Noutro texto (Fernandes, 2017), escrevíamos: "Comunicar as práticas científicas - métodos, resultados, processos de trabalho, debates sobre polémicas e controvérsias sobre métodos, resultados e processos de trabalho - é uma prática antiga em ciência. No campo da psicologia as primeiras publicações surgem na década de 60 do século XIX, no domínio que a estabeleceria como ciência: a psicologia experimental e fisiológica" (Fernandes, 2017, p. 31).

Entre 1878 e 1886, década em que é fundado o laboratório de Leipzig dirigido por Wilhelm Wundt, são publicados um total de 117 artigos (Caparrós, 1980) - algo que pode bem hoje estar na contabilidade pessoal de um único investigador.

Nunca como hoje a publicação foi tão incentivada, nunca como agora o seu principal formato - o artigo científico - teve tal incremento, como constataremos ao longo deste texto. 0 sistema da ciência é, em simultâneo, uma força motriz da mudança social e um campo sujeito a esta mudança - isto é, é mudado por aquilo que ele próprio ajudou a mudar. Vivemos desde o final do século passado um período marcado pela afirmação da esfera privada, em que o mercado se erige como a instância no centro das decisões - isto é, em que se reforça enquanto poder.

O sistema da ciência não é imune a estas forças de pressão, como é bem o exemplo a diminuição do financiamento estatal das universidades públicas, em sintonia com a tendência a tornar o ensino e a investigação em atividades situadas no espaço do mercado. Num espaço destes a circulação de produtos quer-se rápida, e a sua contabilização produz indicadores de produtividade que importam para a visibilidade necessária ao mercado, que é como sabemos um espaço que se mantém competitivo através da sua própria publicitação. É nesta dinâmica que podemos ler a atual importância dada aos rankings das universidades, fulcrais para a captação de recursos. E ser competitivo nestes rankings tem como elemento fulcral a capacidade de geração de artigos científicos por parte das instituições universitárias e centros de investigação. A autoria é assim decisiva para esta competitividade, tanto ao nível do sucesso individual dos investigadores como do sucesso das instituições. A importância atribuída ao "fator de impacto" é bem a imagem desta nova ordem que tem vindo a tornar-se dominante - e a própria escolha do vocábulo "impacto" é bastante auto-explicativa.

O paper - como é designado correntemente o artigo científico - assume, pois, um papel central, a escrita de papers e a obtenção de êxito na sua submissão ao circuito das publicações torna-se tarefa premente para os investigadores. Não é exagerado dizer-se que existe atualmente no contexto académico uma pressão para a publicação. Poderíamos reunir múltiplos sinais disso, como a obrigatoriedade de publicar já no decurso dos programas doutorais, o incentivo à realização das teses de doutoramento sob a forma de artigos publicados em revistas internacionais, a contagem do número de papers como importante indicador da avaliação de desempenho nas carreiras docentes ou a importância de publicar em revistas com fator de impacto na captação de financiamentos a projetos de pesquisa.

Mapeámos já noutro lugar (Fernandes, 2017) uma série de alterações em todo o ciclo de produção de conhecimento científico: consequências da pressão crescente para a publicação (por exemplo encurtamento do tamanho dos papers, aumento do número de autores por artigo), centralidade do paper em detrimento de outras formas de comunicação em ciência, aumento das regras de padronização em torno da forma de escrita, bem como normas para as referências bibliográficas utilizadas, entre muitos outros exemplos. Advogávamos nesse texto que estas alterações têm influência no conhecimento produzido (por exemplo, menor tempo de maturação dos resultados, publicação ainda em fases intermédias do processo de pesquisa, como respostas à pressão para publicar).

O aumento exponencial da produção científica tem vindo a tornar cada vez mais difícil a organização e atualização de cada investigador numa determinada área de saber. A sistematização da grande massa de informação produzida é um desafio imperativo na sociedade do conhecimento, exigindo, no caso da ciência, novas competências aos seus praticantes. Neste contexto, surgiram os indexadores de artigos, grandes bases de dados que permitem uma consulta rápida das principais e mais recentes publicações tendo em 
linha de conta determinadas disciplinas científicas e certas palavras-chave. A concentração da produção científica nestas bases é um terreno aberto à construção de indicadores (Hicks et al, 2015; Hirsch, 2005).

Porém, este estado de coisas tem sido objeto de várias críticas. Billig (2013) e Martinez e Tarrès (2013), por exemplo, socorrem-se do conceito de capitalismo cognitivo para enquadrar a forma como se privilegia a produtividade e o número de publicações. Paralelamente a esta evolução, temos também a emergência de indicadores de sucesso que, tendo como base o Fator de Impacto (FI), se multiplicaram num sem número de fórmulas e algoritmos (Altbach, 2015).

A produção científica nacional na área da psicologia teve de acompanhar estas mudanças. A publicação faz-se agora tendo em linha de conta as revistas internacionais com maior impacto e utilizando maioritariamente a língua inglesa. É bem provável que uma consequência disto seja a indução de um desfasamento entre o local em que a investigação é conduzida e o lugar onde ela vem a lume, tal como já sublinhado em Tinoco (2013). Fica assim por cumprir uma fase importante do ciclo científico apontado por Morin (1990): a devolução dos resultados às comunidades em que os próprios cientistas se encontram inseridos e onde conduziram os seus questionamentos.

0 presente trabalho pretende aprofundar a reflexão de que já se deu conta anteriormente (Fernandes, 2017; Tinoco, 2013). Operacionalizaremos algumas destas reflexões em objetivos de pesquisa, mapeando em seguida evidências empíricas que as sustentem. 0 esforço que empreenderemos está também aberto aos dados que poderão surgir no decurso das nossas pesquisas de natureza, sobretudo, bibliométrica.

\section{Objetivos}

Pretendemos situar a produção científica portuguesa na área das ciências sociais, mas sobretudo da psicologia, de acordo com parâmetros quantificáveis. Queremos, assim, conhecer alguns padrões quantitativos emergentes em grandes bases de dados nacionais e internacionais, questionando-os numa série de áreas. Vejamos algumas das nossas interrogações: o que é medido na produção científica contemporânea? (Medições); de que forma a autoria científica se apresenta hoje em dia no que diz respeito aos trabalhos e autores com maior impacto? (Autorias); quais são os temas e os formatos científicos que obtêm maior visibilidade nas grandes bases de dados internacionais? (Temas de Escrita); de que forma os periódicos portugueses na área das ciências psicológicas se projetam internacionalmente? (Revistas Científicas Portuguesas na Área da Psicologia); em que escalas de valorização estão inseridos os investigadores e trabalhos científicos nacionais na psicologia? (Valorizações); finalmente, dedicaremos alguma atenção a perceber atuais e futuras tendências bibliométricas (Outras Métricas).

\section{MÉTODO}

As fontes para a nossa recolha de dados serão as seguintes bases: Pordata; Scopus e SCImago; Web of Science e Journal of Citation Report. Pretendemos, através da consulta de métricas, conhecer a realidade da publicação científica nacional na área da psicologia, tendo em linha de conta as várias áreas desta ciência consideradas nestas bases. Trata-se, sobretudo, de questionar dados quantitativos aí disponibilizados a partir da série de indagações levantadas no ponto anterior.

A Pordata é uma base de dados sobre diversos aspetos da realidade portuguesa. Disponibiliza também dados sobre o estado da ciência em Portugal e tem em linha de conta diversas áreas científicas, incluindo as ciências sociais. Utiliza diferentes fontes independentes, entre as quais sobressai o Instituto Nacional de Estatística e o Eurostat. Este instrumento, que está online e é gratuito, foi criado em 2009 pela Fundação Francisco Manuel dos Santos (Pordata, 2019).

Em relação às grandes bases de dados internacionais, temos a Scopus, propriedade da Elsevier, que concentra grande número de periódicos e publicações na área das ciências sociais e humanas, nomeadamente a psicologia; a SCImago Journal Rank (SJR) é um valioso instrumento, no sentido de medir a influência de revistas e da produção científica. Neste último indicador, são combinados o número de citações obtidas pelos trabalhos publicados numa determinada revista, assim como o prestígio de cada uma dessas citações.

Por outro lado, na Scopus, poderemos mapear os autores com maior impacto científico, bem como os artigos com mais impacto - sempre tendo em linha de conta a filiação portuguesa. 0 impacto, nesta base de dados, tem que ver com o número de citações obtidas, quer por determinado autor, quer ainda por um artigo científico específico.

Em relação ao Web of Science, Falagas et al. (2008) consideram tratar-se de uma incontornável base de dados. Trata-se de um instrumento central, propriedade da Clarivate Analytics e anteriormente da Institute for Scientific Information ISI (fundada por Eugene Garfield) que fornece dados em termos de citações e da evolução dessas mesmas citações. Também poderemos perceber uma série de dados em 
termos de rankings e seriação de artigos, pois esta base de dados disponibiliza os campos de psicologia e ciências sociais. Estes dados poderão também ser recolhidos através da Journal Citation Reports (JCR), que operacionaliza e quantifica dados que estão na Web of Science.

Realizámos pesquisas socorrendo-nos de todos estes instrumentos, por forma a conseguirmos dados e informações que dessem suporte empírico a um trabalho teórico anteriormente realizado por um de nós (Fernandes, 2017). Estas pesquisas estiveram também abertas aos dados novos, no sentido de serem imprevistos, e que depois deram suporte aos campos temáticos já referidos um pouco mais acima.

\section{RESULTADOS}

Realizámos uma série de pesquisas nas três bases de dados anteriormente referidas, consultando os dados disponibilizados tendo em linha de conta algumas áreas temáticas que enumerámos nos Objetivos. Passaremos agora à apresentação das pesquisas realizadas.

\section{Medições}

Quais são as estatísticas e os números que podem ser obtidos através destes instrumentos? A ciência parece ser medida em termos quantitativos, nomeadamente através de contabilizações: número de publicações, número de citações; número de autorias; coautorias nacionais e internacionais; número de trabalhos em open science e "protegidos" por paywall) 3 .

Este afã quantitativo concentra-se sobretudo na questão dos papers - artigos científicos que são publicados em revistas indexadas em grandes bases de dados. Para além destes, são ainda considerados os resumos de comunicações, as atas e outros documentos. 0 capítulo de livro ou mesmo o livro, por exemplo, não surgem tanto nestas pesquisas.

Assim, o número de publicações em formato paper de autores nacionais tem vindo a aumentar, independentemente da base considerada. A Pordata, numa análise que inclui dados de 1981 a 2015, regista um aumento de artigos na categoria "Ciências Sociais" mais notório a partir de 2002, e que se aproxima de um perfil exponencial por volta de 2009 (pesquisa efetuada em abril 2019). Outro aspeto importante a ter aqui em linha de conta são as citações registadas em "Revistas internacionais" que, segundo a Pordata, em 2015 alcançou o número de 21.333 - cifra essa que ainda pode sofrer um aumento à medida que novos trabalhos publicados efetuem novas citações. 0 mesmo acontece tendo como unidade de medida o número de publicações citadas em revistas internacionais. Em relação às co-autorias, tendo em linha de conta os dados da Pordata, temos um perfil semelhante ao do número de publicações: um aumento que toma o perfil próximo do exponencial a partir de 2009.

Em relação à Scopus e relativamente ao número de publicações de artigos de autores nacionais indexados, é possível obter registos desde 1953. 0 crescimento é quase insignificante até 1998 e tem alguma relevância entre este ano e 2007. A partir desta data até 2017, ano limite dos registos no momento em que realizámos esta pesquisa (março de 2019), o crescimento torna-se explosivo: em 2007 o número de publicações rondava as 100 e no momento mais recente 850 .

A SCImago possibilita ainda o acesso ao número de citações e autocitações obtidas pelos trabalhos de autoria nacional. Quisemos conhecer este padrão relativamente à área geral da psicologia. 0 número é crescente desde 1996 até 2010, ano em que se alcançou um pouco mais de 5000 citações. Em relação às autocitações, elas tiveram também um momento de crescimento até estabilizarem em torno das 1000 autocitações/ano. 0 número de citações regista uma diminuição a partir de 2012, o que é comum neste tipo de registos, pois só decorrido mais tempo é que conseguimos perceber as citações alcançadas pelos trabalhos nacionais num determinado ano mais recente. A estabilização das autocitações que se observa desde 2012 já é diferente, tratando-se de um número próximo do definitivo. Este dado é tanto mais relevante se tivermos em linha de conta o aumento significativo do número de publicações.

Em relação à Web of Science (pesquisas efetuadas em abril 2019), temos também um crescendo do número de publicações - os registos aqui vão desde o ano 2000 a 2019. De 2016 a 2018, o número de publicações oscilou entre as 600 e 700 publicações/ano. No que diz respeito às citações, alcançou-se em 2018 o número de 10.000 . Note-se que, num percurso sempre crescente, apenas em 2008 se atingiu a marca de 1000 citações. De 2008 em diante, o crescimento é cada vez mais acentuado a cada ano que passa.

Temos, então, como principais unidades de medida, o artigo publicado em revistas científicas admitidas nas grandes bases de dados internacionais e as citações obtidas por cada um deles em trabalhos vindos a lume nas mesmas circunstâncias. Temos ainda uma narrativa de sucesso: cada vez mais publicações, cada vez mais citações. Este sucesso também inclui uma vertente ortopédica: as autocitações,

3 Open science tem que ver com uma atitude de partilha de resultados e de investigações que normalmente pressupõe o seu acesso gratuito - ficando assim em open access. Por consequência, paywall remete para todas as situações em que os artigos têm de ser pagos pelo leitor ou pela biblioteca que assina determinada base de dados. 
que são vistas quase como desonestidades bibliométricas (Larsen-Dahler, 2019), não têm aumentado, pese embora o crescimento do número de publicações.

No que concerne à questão do acesso aos artigos, concretamente se estão ou não em open access, realizámos duas pesquisas. Em termos de toda a produção de filiação nacional, ainda tendo em linha de conta trabalhos considerados na Scopus, poderemos constatar a seguinte distribuição no que à produção nacional de psicologia diz respeito: 1226 trabalhos em open science; 5.656 noutros formatos - protegidos, na maioria dos casos, por paywall. Socorrendo-nos ainda da mesma base de dados, e tendo apenas em linha de conta os 20 autores nacionais na área da psicologia com mais citações, temos 154 trabalhos em open access num universo de 1223 artigos.

\section{Autorias}

A Pordata regista o número de artigos científicos por doutoramento realizado na área das ciências sociais. Regista-se a média inicial de 2,8 em 1981, subindo para 7,2 no último ano em que os registos são disponibilizados - 2017. Sublinha-se ainda que a contagem se refere ao artigo científico publicado em revista. A escrita de teses de doutoramento parece cada vez mais preocupar-se com o formato paper. A escrita de investigadores ainda em formação começa a ser logo desde o início, e cada vez mais, submetida à questão das métricas, da publicação de papers em revistas consideradas em grandes bases de dados internacionais.

A pesquisa efetuada na Scopus, já anteriormente referida, permitiu ainda conhecer os 20 autores mais citados em termos nacionais, no que à área da psicologia diz respeito. Depois, fizemos um mapeamento quantitativo de autorias em relação a uma série de parâmetros, a saber: autoria exclusiva; coautoria em que o visado é autor principal; coautoria em que o visado é autor secundário e finalmente coautorias em que existem mais de seis assinaturas (discriminando ainda se, nestes trabalhos, o visado é autor secundário ou principal). Na Tabela 1, poderemos observar o padrão de assinaturas dos 20 autores nacionais com maior impacto em periódicos registados na Scopus:

Tabela 1. Padrão de autorias (20 autores de topo)

\begin{tabular}{cccccc}
\hline $\begin{array}{c}\text { Autoria } \\
\text { exclusiva }\end{array}$ & $\begin{array}{c}\text { Coautoria } \\
\text { principal }\end{array}$ & $\begin{array}{c}\text { Coautoria } \\
\text { secundária }\end{array}$ & $\begin{array}{c}\text { Coautoria } \\
\text { principal (mais } \\
\text { de 6 } \\
\text { assinaturas) }\end{array}$ & $\begin{array}{c}\text { Coautoria } \\
\text { secundária } \\
\text { (mais de 6 } \\
\text { assinaturas) }\end{array}$ & $\begin{array}{c}\text { Total de } \\
\text { artigos }\end{array}$ \\
\hline 48 & 160 & 771 & 38 & 206 & 1223 \\
\hline
\end{tabular}

Como poderemos constatar na tabela 1, mais de metade dos artigos são obtidos em coautorias secundárias e em coautorias secundárias de trabalhos com mais de seis assinaturas (771+206, respetivamente). A coautoria principal de artigos obteve a cifra de 160 e a coautoria principal de trabalhos com mais de 6 assinaturas - correspondendo muitas delas à liderança de projetos envolvendo redes internacionais -, registou 38 trabalhos. Realçamos também a perda de expressão da autoria exclusiva, 48 trabalhos - tanto mais que um dos autores considerados assinou sozinho 39 dos papers com esse tipo de assinatura.

Note-se que alguns autores desta amostra nunca assinaram nenhum trabalho em que foram autores exclusivos e alguns deles, também, não assinaram trabalhos em que foram coautores principais. Assim, de entre os autores com melhores indicadores bibliométricos, alguns deles remetem-se aos dois tipos de coautorias secundárias consideradas.

Fizemos depois, na mesma base, um levantamento no interior da mesma amostra dos 20 autores, mas agora relativamente ao número de publicações nos anos 2016-2017-2018. Como de resto, observamos na Tabela 2:

Tabela 2. Número de publicações últimos três anos (20 autores de topo)

\begin{tabular}{cccc}
\hline & $\mathbf{2 0 1 6}$ & $\mathbf{2 0 1 7}$ & $\mathbf{2 0 1 8}$ \\
\hline Número de publicações & 132 & 158 & 148 \\
\hline
\end{tabular}

Poderemos constatar que existe uma média de quase oito artigos por autor/ano em 2017, por exemplo. Individualmente, alguns autores deste top 20 chegaram a mais de 20 artigos publicados por ano.

Mapeámos também os 20 artigos mais citados na Scopus e obtivemos um conjunto de trabalhos publicados entre 1996 e 2012 que quisemos caracterizar segundo uma série de parâmetros. Em primeiro lugar, o número de assinaturas: somente um trabalho tinha autoria única, sendo que cerca de metade dos artigos têm 10 ou mais assinaturas, tendo inclusive um deles 96. Todos os trabalhos foram escritos em 
inglês. As citações obtidas variaram entre as 1375 no mais citado e as 306 citações para o trabalho que encerrou a nossa lista. Quanto à sua natureza, mais de metade (cerca de 11) correspondem a investigações cross-cultural envolvendo várias nacionalidades e 6 a trabalhos de revisão ou de meta-análise. Restam três artigos, um de caráter experimental, outro propondo um método estatístico e um último aplicando um método matemático para trabalhar com grande quantidade de dados num determinado padrão de preferências.

Entre os 20 artigos que têm maior número de citações, estamos perante dois grandes grupos: um primeiro conjunto de trabalhos de revisão de um determinado tema ou conceito (o que potencialmente interessará um maior conjunto de leitores); e um segundo conjunto, que engloba trabalhos de natureza internacional, ao pretender estudar um determinado conceito numa série de países, o que por vezes corresponde a trabalhos com mais de 10 assinaturas.

Ainda em relação a questões autorais, temos que apenas um destes artigos é de autoria única; sendo que, no universo de 20 trabalhos, apenas 4 artigos correspondem a coautorias em que o autor principal é de filiação nacional. Dito de outra forma, em três quartos desta amostra os autores de filiação nacional estão na posição de coautores secundários.

A Web of Science permite ainda conhecer a nacionalidade das coautorias dos trabalhos com autores filiados no nosso país e que escreveram sobre psicologia. Assim, num universo de 6,776 trabalhos indexados nesta base, 855 foram também assinados por autores dos EUA; 625 por autores espanhóis; 563 ingleses. Surge também o Brasil com 323; a Holanda com 305; seguindo-se depois países como a Itália, a França e a Alemanha.

\section{Temas de escrita}

Relativamente à SCImago (referente à Scopus - pesquisa efetuada em março de 2019) temos as seguintes categorias: "Psychology miscelaneous" com 1849 documentos; "Developmental and Educational Psychology", 1078 documentos; "Clinical Psychology" 967 documentos; "Applied Psychology", 851 documentos; "Social Psychology" 847 documentos; "Experimental and Cognitive Psychology", 637 documentos e "Neuropsychology and Physiological Psychology", 293 documentos. Para além de uma categoria indiferenciada, temos que os temas relacionados com a psicologia do desenvolvimento são os que mais motivam a escrita. Seguem-se a psicologia clínica, a psicologia aplicada e ainda a psicologia social.

Relativamente à produção científica de autores portugueses na área da psicologia na Web of Science, obtivemos os seguintes dados (no universo de 6,776 trabalhos resultantes da nossa pesquisa): 34,3\% "Psychology Multidisciplinary"; 23,2\% "Psychology". Em terceiro lugar, temos a "Psychology Clinical" com 16,1\%; a "Psychology Experimental" com 13,0 \%; a "Psychology Applied" com 10,6\% e a "Psychiatry" com 10,0\%. Terminam o top 10 a "Psychology Social" (7,6\%); a "Public Environmental Occupational Health" (6,1\%) e a "Psychology Educational" (5,4\%) - (abril 2019).

Ainda de acordo com esta última base de dados e tendo em linha de conta a língua em que os trabalhos foram escritos, podemos constatar que no universo dos 6,779 artigos, 6311 foram escritos em inglês, 246 em português e 179 em espanhol, de seguida vem o francês com 32 trabalhos. Existem outras línguas como o alemão e o russo, mas com expressão residual.

Para além das categorias gerais, os temas da psicologia clínica têm expressão predominante em ambas as bases de dados. Depois, na Web of Science, realçamos a "Psychology Experimental" e a "Psychology Applied". Já na Scopus temos a "Developmental and Educational Psychology" e a "Applied Psychology". Tornase difícil fazer aqui generalizações, uma vez que as categorias não são coincidentes nas duas bases de dados. Existem também categorias de caráter geral com fortes representações nas duas bases de dados ("Psychology miscelaneous" na SCImago e "Psychology Multidisciplinary" na Web of Science).

\section{Revistas científicas portuguesas na área da psicologia}

Que revistas científicas portuguesas na área da psicologia estão presentes em alguma das duas bases de dados internacionais que temos estado a considerar? Fomos conhecer um pouco o ranking das revistas de psicologia através da SCImago. Em termos de revistas de psicologia nacionais indexadas na Scopus em 2017, temos a Análise Psicológica, que se situa no quartil 4 (0.160 no SJR - Scientific Journal Ranking); a Revista Crítica de Ciências Sociais (quartil 4; 0.120 no SJR), a Psicologia (quartil 4; 0.102 no SJR) e a Social Inclusion (quartil 3; 0.395 no SJR). Também tendo em conta o mesmo ano temos, na categoria "Developmental and Educational Psychology", a European Psychology of Education4 (quartil 2; 0,790 no SJR) - pesquisas efetuadas em março de 2019 na SCImago.

${ }^{4}$ Esta revista científica publicada pelo Instituto Superior de Psicologia Aplicada (ISPA) está atualmente em regime de co-propriedade com a Springer Nature B.V., pelo que deixou de ser considerada como portuguesa nesta importante base de dados em pesquisas posteriormente por nós efetuadas. 
Em termos de revistas de psicologia nacionais, algumas notas temporais: em 2009 não tínhamos qualquer periódico indexado. Já em 2010, a Análise Psicológica entra para se situar sempre no quartil 4, exceto em 2012 e 2016, em que se situou no quartil 3. Em 2013 entra a Social Inclusion, em 2015 a Revista Crítica de Ciências Sociais e em 2017 entra também a Psicologia ${ }^{5}$. Todas estas revistas encontram-se em regime de open access.

Poderemos constatar, conforme a Tabela 3, que de uma forma geral que as revistas portuguesas têm bastante dificuldade em entrar no SJR e em manter-se lá de forma sustentada. A este respeito, apenas o European Journal of Psychology of Education (EJPE) conseguiu recentemente entrar no Quartil 2 - note-se que a revista é exclusivamente em inglês, sendo este um fator importante na compreensão destes resultados, porque potencia a possibilidade de aumentar o número de citações.

Tabela 3. Revistas portuguesas na àrea da psicologia - classificação na SJR

\begin{tabular}{|c|c|c|c|c|c|c|c|c|c|c|c|c|c|c|c|c|c|c|c|}
\hline Revista & 99 & 00 & 01 & 02 & 03 & 04 & 05 & 06 & 07 & 08 & 09 & 10 & 11 & 12 & 13 & 14 & 15 & 16 & 17 \\
\hline $\begin{array}{l}\text { Social } \\
\text { Inclusion }\end{array}$ & $\mathrm{s} / \mathrm{d}$ & $s / d$ & $\mathrm{~s} / \mathrm{d}$ & $\mathrm{s} / \mathrm{d}$ & $s / d$ & $\mathrm{~s} / \mathrm{d}$ & $s / d$ & $\mathrm{~s} / \mathrm{d}$ & $\mathrm{s} / \mathrm{d}$ & $\mathrm{s} / \mathrm{d}$ & $\mathrm{s} / \mathrm{d}$ & $\mathrm{s} / \mathrm{d}$ & $\mathrm{s} / \mathrm{d}$ & $\mathrm{s} / \mathrm{d}$ & E & Q4 & Q4 & Q3 & Q3 \\
\hline EJPE & Q3 & Q3 & Q3 & Q3 & Q3 & Q4 & Q4 & Q4 & Q3 & Q3 & Q3 & Q3 & Q3 & Q3 & Q3 & Q3 & Q2 & Q2 & Q2 \\
\hline $\begin{array}{l}\text { Rev. Crít. } \\
\text { Ciências } \\
\text { Soc. }\end{array}$ & $\mathrm{s} / \mathrm{d}$ & $s / d$ & Ent & Q4 & Q4 & Q4 & $\mathrm{s} / \mathrm{d}$ & $\mathrm{s} / \mathrm{d}$ & $\mathrm{s} / \mathrm{d}$ & $\mathrm{s} / \mathrm{d}$ & $\mathrm{s} / \mathrm{d}$ & $\mathrm{s} / \mathrm{d}$ & $\mathrm{s} / \mathrm{d}$ & $\mathrm{s} / \mathrm{d}$ & $\mathrm{s} / \mathrm{d}$ & $\mathrm{s} / \mathrm{d}$ & E & Q4 & Q4 \\
\hline $\begin{array}{l}\text { Análise } \\
\text { Psic. }\end{array}$ & $s / d$ & $s / d$ & $s / d$ & $\mathrm{~s} / \mathrm{d}$ & $s / d$ & $\mathrm{~s} / \mathrm{d}$ & $\mathrm{s} / \mathrm{d}$ & $\mathrm{s} / \mathrm{d}$ & $\mathrm{s} / \mathrm{d}$ & $s / d$ & $\mathrm{~s} / \mathrm{d}$ & E & Q4 & Q3 & Q4 & Q4 & Q4 & Q3 & Q4 \\
\hline Psicologia & $s / d$ & $\mathrm{~s} / \mathrm{d}$ & $\mathrm{s} / \mathrm{d}$ & $\mathrm{s} / \mathrm{d}$ & $\mathrm{s} / \mathrm{d}$ & $\mathrm{s} / \mathrm{d}$ & $\mathrm{s} / \mathrm{d}$ & $\mathrm{s} / \mathrm{d}$ & $\mathrm{s} / \mathrm{d}$ & $\mathrm{s} / \mathrm{d}$ & $\mathrm{s} / \mathrm{d}$ & $\mathrm{s} / \mathrm{d}$ & $\mathrm{s} / \mathrm{d}$ & $\mathrm{s} / \mathrm{d}$ & $\mathrm{s} / \mathrm{d}$ & $\mathrm{s} / \mathrm{d}$ & $\mathrm{s} / \mathrm{d}$ & $\mathrm{E}$ & Q4 \\
\hline
\end{tabular}

Em relação a revistas portuguesas de psicologia incluídas no Web of Science, o panorama é confrangedor. Assim, de acordo com consulta do Journal of Citation Reports (JCR), apenas a European Journal of Psychology of Education se encontra indexada. Trata-se de uma revista temática na área da psicologia da educação que não se encontra em open access e que apenas aceita trabalhos em língua inglesa.

No que diz respeito às filiações das revistas anteriormente citadas, temos a European Journal of Psychology of Education editada pela Springer Netherlands; a Análise Psicológica editada pelo Instituto Superior de Psicologia Aplicada (ISPA); a Revista Crítica de Ciências Sociais editada pelo Centro de Estudos Sociais da Universidade de Coimbra e de caráter multidisciplinar; finalmente, temos a Psicologia, editada desde 1980 pela Associação Portuguesa de Psicologia. A Social Inclusion é editada pela Cogitatio Press, só aceita trabalhos em inglês e não se interessa apenas por trabalhos na área da psicologia.

\section{Valorizações}

0 valor base situa-se em torno das citações que cada artigo consegue obter. A partir daí tecem-se uma série de indicadores bibliométricos que permitem a construção de rankings não só de autores, mas de revistas científicas e até de instituições universitárias. A lógica é, pois, a de competição e quantificação que depois se materializa nas decisões relativas a financiamentos.

A Web of Science disponibiliza as fontes de financiamento dos artigos publicados, caso existam. Assim, num universo de 6776 publicações, 896 trabalhos foram financiados. 0 financiamento é quase exclusivo da Fundação para a Ciência e Tecnologia (FCT), que surge grafado de diferentes maneiras na pesquisa; e 51 trabalhos financiados pelo Fundo Europeu de Desenvolvimento Regional (FEDER).

A Web of Science disponibiliza ainda a filiação institucional dos autores nacionais que assinaram artigos em revistas aceites por esta base de dados. Em abril de 2019 registámos os resultados que apresentamos de seguida. Estamos perante uma maioria de instituições ligadas ao ensino superior, como a Universidade de Lisboa (com 1794 artigos publicados); a Universidade do Minho (1212); a Universidade de Coimbra (1058); Universidade do Porto (997), entre outras universidades ${ }^{6}$. Realçamos já num lugar mais abaixo, o Hospital de Santa Maria com 155 publicações, uma vez que se trata de uma instituição não universitária que desenvolve trabalho de investigação.

A SCImago considera as seguintes áreas da psicologia: "Applied Psychology"; "Clinical Psycholoy"; "Developmental and Educational Psychology"; "Experimental and Cognitive Psychology"; "Neuropsychology and Psysiological Psychology"; "Psychology miscelaneous"; "Social Psychology". Para cada uma delas, procurámos o ranking em que Portugal se encontrava, quantificando uma série de parâmetros, a saber:

\footnotetext{
${ }^{5}$ Daqui se exclui a publicação de uma conferência que acabou por ter impacto alguns anos a seguir à sua realização: MCCSIS'08 - IADIS Multi Conference on Computer Science and Information Systems; Proceedings of ICT, Society and Human Beings, vinda a lume em 2008.

${ }^{6}$ Os dados dizem respeito ao número de artigos publicados por instituição. Trata-se de dados brutos que não são relativizados em função do número de professores e investigadores de cada uma delas - assim, não se poderá fazer uma comparação direta destes números.
} 
número de documentos publicados; número de documentos citáveis; número de citações obtidas; número de autocitações; número médio de citações que cada publicação obteve e ainda o seu H Index ${ }^{7}$.

Considerámos ainda o período temporal de 1996-2017 e como se encontravam as mesmas quantificações no último ano disponível na SCImago, 2017. A produção científica nacional, tida no seu todo (pesquisa efetuada em março de 2019), situa Portugal na 31. ${ }^{-}$posição mundial, com cerca de 270.634 documentos; 251.622 documentos citáveis considerados que geraram e 3.832 .603 citações e 700.532 autocitações. Cada documento gerou em média 14.16 citações e um H Index de 416. Tratam-se de dados brutos que não têm em linha de conta a dimensão e os recursos científicos de cada comunidade científica nacional.

A SCImago disponibiliza ainda um ranking por países e áreas científicas da psicologia. No que respeita à produção científica na área da psicologia (a categoria "Psychology miscelaneous"), Portugal situase na 21. a posição, com 1849 documentos. Em termos de Psicologia Clínica (categoria: "Clinical Psychology"), Portugal situa-se na 29. ㅁ posição com 967 documentos. No que concerne à categoria "Social

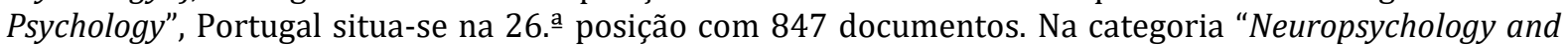
Psysiological Psychology", Portugal situou-se na 27. a posição com 293 documentos. Na categoria "Experimental and Cognitive Psychology", o nosso país situou-se na 25. a posição com 637 documentos. Na categoria "Developmental and Educational Psychology", situou-se na 28. - posição com 1078 documentos; 1052 documentos citáveis. Na categoria "Applied Psychology", Portugal situou-se na 25. a posição com 851 documentos. Assim, comparativamente com o ranking geral alcançado pela ciência portuguesa tida no seu todo (31. - posição mundial), a psicologia, também considerada no seu conjunto, obteve uma posição 10 lugares acima (21. $\left.{ }^{a}\right)$. Ainda em termos de áreas internas a categoria "Applied Psychology" classificou-se também na 25. - posição.

Está bastante claro que estas valorizações e classificações de produtividade têm essencialmente em linha de conta as publicações, as citações obtidas e outros índices que foram sendo propostos pela bibliometria, tendo por base essas mesmas citações.

\section{Outras métricas}

Tentámos traçar de uma forma global algumas das tendências e valorações que estão inscritas em duas das principais bases de dados internacionais e numa base nacional. Percebemos a necessidade de construir indicadores que permitam seriações com base na unidade básica (paper) e nas citações que cada desses papers consegue obter - Impact Factor. A construção posterior de indicadores mais complexos é progressiva: H Index ou a construção de algoritmos (Hirsch, 2005). A Web Of Science e a Scopus permitem ainda seriar as pesquisas de acordo com o tema "relevância". Esta forma de seriação tem que ver com a aplicação de fórmulas matemáticas que acabam por considerar uma citação mais importante do que outra. Por exemplo: o meu artigo que tem 10 citações é mais relevante do que outro com o mesmo número de citações, uma vez que os trabalhos que citaram o meu têm, por sua vez, mais citações. Esta complexidade matemática permite a introdução da importância dos trabalhos que citam o meu; a importância das revistas científicas em que os trabalhos que citaram o meu foram publicados, entre outras subtilezas (Fernandes, 2017; Haro, 2017).

Estas novas métricas vão para além da dimensão mais estritamente bibliométrica. Existe também um esforço recente que tem que ver com a forma como cada paper se comporta como objeto no mundo digital. Trata-se não só de contabilizar o número de consultas que cada trabalho obtém, mas ainda o número de descarregamentos eletrónicos por utilizadores individuais ou conversas sobre o mesmo acontecidas em redes sociais e outras. Estas performances do trabalho científico são objeto de interesse, por exemplo, da Altmetric (Adie \& Roe, 2013; Melero, 2015).

Buschman \& Michalek (2013) tentam sistematizar várias áreas de impacto para além das citações, propondo: a "Usage", que compreende os descarregamentos e as leituras online; a "Capture", que compreende as leituras, os grupos, a marcação como favoritos entre outros; as "Mentions" em histórias, blogues, comentários, textos de revisão ou ainda referências em entradas da Wikipédia; e finalmente os "Social Media" em que se contabilizam Tweets, Likes +1 , Shares e Ratings.

\section{REFLEXÕES FINAIS}

Através de diversas quantificações, tendo como elemento analítico principal o paper, mapeámos algumas características e tendências quer no que diz respeito à questão das autorias, quer ainda no que diz respeito ao próprio paper e ao impacto das revistas científicas nas bases de dados internacionais.

${ }^{7} \mathrm{O}$ H índex foi proposto por Hirsh e tem em conta o número máximo de trabalhos que tenham o maior número de citações (Hirsh, 2005). Assim, por exemplo, um $\mathrm{H}$ índex de 10 significa que um determinado autor assina dez trabalhos com pelo menos dez citações cada um. 
Em relação ao artigo científico, há um contínuo aumento do seu número a cada ano, mais expressivo a partir do final da primeira década deste século; é escrito maioritariamente em inglês; normalmente é acedido através de pagamento; e vem a lume em revistas científicas internacionais - isto é, que estejam indexadas em bases de dados de dimensão mundial. Estas constatações suportam os pontos de partida que enunciámos na introdução: existe uma pressão para a publicação que se manifesta no aumento contínuo do número de artigos, a sua publicação responde a uma lógica económica em que eles detêm um valor, esta lógica globalizou-se (as bases de dados são internacionais, a comunicação da ciência faz-se maioritariamente em inglês), esta globalização, à semelhança da globalização mais geral, acentuou-se a partir da viragem do milénio. Notar que é também nesta época que surgem os primeiros rankings das universidades e que se criam os indicadores bibliométricos com os quais se pretende aferir a importância relativa dos produtos em circulação.

É curioso assinalar o seguinte: o paper constitui-se como uma singular mercadoria, posto que o seu produtor, o autor, paga frequentes vezes para a colocar no mercado, ao invés de receber. Podemos conjeturar que a expectativa de lucro é diferida no tempo, pois o autor acredita que o seu paper representa um capital que lhe valerá mais adiante - doutro modo, publicar em revistas que cobram seria incompatível com a racionalidade económica e elas, muito provavelmente, não sobreviveriam.

Os artigos que conseguem obter mais citações referem-se a estudos de meta-análise e a investigações de caráter transcultural, em que a autoria nacional vem a propósito da réplica de determinado estudo na realidade portuguesa. Dada a pressão para a publicação, torna-se atraente publicar este género de artigos: revisões sistemáticas de literatura, trabalhos que sejam suscetíveis de captar atenção em vários contextos e geografias, como são os transculturais.

As revistas científicas nacionais na área da psicologia têm dificuldade em ser incluídas nestas bases internacionais em que pesquisámos. Temos quatro revistas ${ }^{8}$ na Scopus e apenas uma na Web Of Science. As duas revistas com mais impacto são também, como vimos, as que de alguma forma minimizaram a sua componente nacional: uma delas reclama-se europeia e o inglês é a língua de ambas. Os autores ficam, assim, colocados perante uma escolha: ou adequam o paper aos critérios das revistas internacionais melhor indexadas, ou optam por revistas nacionais, de modo a devolver o conhecimento de um modo mais direto às comunidades locais. Esta segunda opção implica o risco de não valorizarem tanto os seus artigos, colocando-os perante um dilema de difícil resolução.

A pesquisa dos 20 autores portugueses com maior impacto na Scopus também nos mostrou um padrão de autoria bastante peculiar: o desaparecimento da assinatura única de trabalhos; a predominância de coautorias secundárias, por vezes em trabalhos com mais de seis assinaturas (nalguns casos até muito mais do que isso). Por outro lado, o número de publicações/ano por investigador é elevado. Em suma, quando analisamos os autores que mais têm conseguido publicar podemos vislumbrar a fórmula para nos tornarmos bons performers, de acordo com aquilo que parece ser mais valorizado pelo capitalismo cognitivo.

Outra tendência que o nosso estudo pôs a descoberto foi a emergência de formas de autoria diluída, em que a reflexividade e expressividade do indivíduo se encontram de algum modo atenuadas. Isto é concomitante com a criação de redes de investigação e o interesse por um recorte dos objetos de estudo que necessita do esforço de uma equipa para ser concretizado.

Esta diluição da autoria, em conjunto com a rarefação de cada artigo considerado individualmente, posto que concorre de ano para ano com mais e mais artigos, pode gerar um paradoxo: esperar-se-ia que ao publicar mais se aumentasse a visibilidade do investigador, quando afinal esta visibilidade fica comprometida pelos efeitos de diluição da autoria e da rarefação do paper.

O levantamento a que procedemos e cujo resultado sintetizamos neste artigo dá um panorama geral da escrita científica nacional na área das ciências sociais, mas sobretudo psicológicas, e procura relacionálas com mudanças mais gerais que estão a ocorrer nas nossas sociedades. 0 sistema da ciência, porque é uma atividade humana que responde a lógicas institucionais, acompanha o modo como estas instituições se adaptam às profundas mutações do nosso tempo. A governamentalidade do sistema da ciência comunica com as formas de governo mais gerais - e daí o acerto da expressão "capitalismo cognitivo", de que o paper é analisador.

No exercício que desenvolvemos ao longo destas páginas utilizamos três instrumentos - dois de impacto internacional e um terceiro nacional. Seria interessante pesquisar estas e outras métricas noutras bases de dados, como a SciELO Citation Index mais para o mundo das publicações em open access; a EBSCOhost para trabalhos em formato e-book; e mesmo bases de dados latino americanas ou mesmo nacionais como a B-on Biblioteca de Conhecimento Online ou a Biblioteca Aberta do Ensino Superior. Aqui

${ }^{8}$ É necessário fazer aqui novamente a ressalva na data da pesquisa: a European Journal of Psychology of Education era considerada portuguesa, o que a 14 de janeiro de 2020 já não acontecia; apesar de ainda ser considerada nacional na Web of Science. 
pesquisaríamos outras formas de publicação, entraríamos em contacto com teses e revistas científicas que não estão indexadas nas bases de dados que privilegiámos neste trabalho.

A análise quantitativa da escrita científica nacional na área das ciências psicológicas permitiu ainda o levantamento de algumas ideias importantes em termos de investigações futuras nesta área: a relação entre os programas de financiamento e produtividade científica; a identificação do tipo de palavras-chave e a relação que estas podem ter com artigos com maior visibilidade; o estudo das redes de assinaturas conjuntas, o que pode desenhar um campo de uma, digamos assim, geografia das comunidades de investigação; a utilização da classificação PsycINFO - American Psychological Association para perceber os formatos de artigos que são mais populares entre a comunidade científica nacional. Finalmente, dentro de uma lógica mais qualitativa, poderia ser interessante debruçarmo-nos sobre categorias emergentes nos resumos dos artigos ou mesmo no que diz respeito ao próprio léxico utilizado.

\section{REFERÊNCIAS}

Adie, E., \& Roe, W. (2013). Altmetric: enriching scholarly content with article-level discussion and metrics. Learned Publishing, 26(1), 11-17. https://doi.org/10.1087/20130103

Altbach, P. (2015). The tyranny of citations. International Higher Education, 43, 3-5. https://doi.org/10.6017/ihe.2006.43.7889

Analytics, C. (2019, Março 28). Web of science core collection. Citation database. Web of Science. https://clarivate.com/webofsciencegroup/solutions/web-of-science-core-collection

Analytics, C. (2019b, Março 28). Journal Citation Reports (JCR). https://clarivate.com/webofsciencegroup/solutions/journal-citation-reports

Billig, M. (2013). Academic words and academic capitalism. Athenea digital: Revista de pensamiento $e$ investigación social, 13, 1, 7-12. https://doi.org/10.5565/rev/athenead/v13n1.1108

Buschman, M., \& Michalek, A. (2013). Are alternative metrics still alternative? Bulletin of the American Society for Information Science and Technology, 39(4), 35-39. https://doi.org/10.1002/bult.2013.1720390411

Caparrós, J. (1980). Los paradigmas en psicologia. CEAC.

Falagas, M. E., Pitsouni, E. I., Malietzis, G. A., \& Pappas, G. (2008). Comparison of PubMed, Scopus, web of science, and Google scholar: strengths and weaknesses. The FASEB Journal, 22(2), 338-342. https://doi.org/10.1096/fj.07-9492LSF

Fernandes, L. (2017). A produção do saber psicológico na sociedade do conhecimento: breve reflexão sobre liberdades e constrangimentos. In L. Fernandes (ed.), Conhecimento de si na sociedade do conhecimento (1a ed, pp. 21-52). Apuro Edições.

Haro, F. A. D. (2017). O impacto de (não) ter impacto: para uma sociologia crítica das publicações científicas. Revista Crítica de Ciências Sociais, 113, 83-106. http://dx.doi.org/10.4000/rccs.6659

Hicks, D., Wouters, P., Waltman, L., De Rijcke, S., \& Rafols, I. (2015). Bibliometrics: the Leiden Manifesto for research metrics. Nature News, 520(7548), 429. https://doi.org/10.1038/520429a

Hirsch, J. E. (2005). An index to quantify an individual's scientific research output. Proceedings of the National academy of Sciences, 102(46), 16569-16572. https://doi.org/10.1073/pnas.0507655102

Larsen-Dahler, P. (2019, Março 30). Ambiguidades e distorções das novas diretrizes acadêmicas. Café História - história feita com cliques. https://www.cafehistoria.com.br/regras-e-ambiguidades

Martínez, M., \& Tarrès, J. (2013). La fábrica de conocimientos: in/corporación del capitalismo cognitivo en el contexto universitário. Athenea Digital, 139-154. https://doi.org/10.5565/rev/athenead/v13n1.1031

Melero, R. (2015). Altmetrics - a complement to conventional metrics. Biochemia Medica, 25(2), 152-160. https://doi.org/10.11613/BM.2015.016

Morin, E. (1990). Introdução ao Pensamento Complexo. Instituto Piaget.

Pordata. (2019, Março 14). Pordata-Base de dados Portugal Contemporâneo. http://www.pordata.pt

SCImago (2019, Março 01). Journal and Country Rank. SCImago Research Group. http://www.scimagojr.com

SCOPUS, F. B. E. (2019, Março 7). Scopus. https://www.scopus.com

Tinoco, R (2013). A citação científica como arma simbólica. Revista Nova Águia, 9(1), 194-195.

$\begin{array}{ll}\text { Historial do artigo } & \\ \text { Recebido } & 01 / 2020 \\ \text { Aceite } & 02 / 2021 \\ \text { Publicado online } & 04 / 2021 \\ \text { Publicado } & 06 / 2021\end{array}$

